INSTITUTE OF SOCIAL STUDIES

\title{
IS SEN'S CAPABILITY APPROACH AN ADEQUATE BASIS FOR CONSIDERING HUMAN DEVELOPMENT?
}

\author{
Des Gasper ${ }^{1}$
}

February 2002

Working Paper Series No. 360

Comments are welcome and should be addressed to the author: c/o ORPAS - Institute of Social Studies - P.O. Box 29776

2502LT The Hague - The Netherlands

workingpapers@iss.nl

${ }^{1}$ Institute of Social Studies, The Hague (gasper@iss.nl). I wish to express thanks for comments from Sabina Alkire, Raymond Apthorpe, Mozaffar Qizilbash, Amartya Sen, Irene van Staveren, audiences at the University of Cambridge in March and June 2001, and anonymous referees. 
The Institute of Social Studies is Europe's longest-established centre of higher education and research in development studies. Post-graduate teaching programmes range from six-week diploma courses to the $\mathrm{PhD}$ programme. Research at ISS is fundamental in the sense of laying a scientific basis for the formulation of appropriate development policies. The academic work of ISS is disseminated in the form of books, journal articles, teaching texts, monographs and working papers. The Working Paper series provides a forum for work in progress which seeks to elicit comments and generate discussion. The series includes the research of staff, $\mathrm{PhD}$ participants and visiting fellows, and outstanding research papers by graduate students.

For a list of available Working Papers and how to order them see the last page of this Working Paper.

Some of the latest Working Papers are published full text (or abstract and content page) on the website: www.iss.nl / Research / Working Papers

For further information contact:

ORPAS - Institute of Social Studies - P.O. Box 29776

2502LT The Hague - The Netherlands - FAX: +31 704260799

E-mail: workingpapers@iss.nl 


\begin{abstract}
:
Sen's capability approach (SCA) has supported valuable work on Human Development $(\mathrm{HD})$, bringing attention to a much wider range of information on people's freedoms and well-being than in most earlier economic planning, but has troubling features and requires modification and enrichment. The paper first identifies the approach's components, the contributions of the HD Reports, and the doubts whether SCA has sufficient conception of human personhood to sustain work on HD beyond finding indices superior to GDP. It then examines SCA's central concepts. The concepts of capability and functioning lead us to consider both possibilities and outcomes, but their definition and use has been confusing. Besides Sen's opportunity concept of 'capability' we must distinguish skills and potentials; and distinguish levels and types of 'functioning'. To understand both consumerism and what can motivate and drive more humanly fulfilling development, we must elaborate different aspects and sources of 'well-being' and the content and requirements of 'agency', more than in Sen's chosen strategy. SCA's priority category of opportunity-capability must be read as a measure of personal advantage relevant in many public policy situations, rather than as a theory of well-being; and its concept of freedom must be partnered by concepts of reason and need.
\end{abstract}




\section{CONTENTS}

1. A puzzle and its possible resolution..........................................................

2. The Capability Approach ...............................................................................

2.1 Real abilities, real humans, real development ? ................................... 8

3. The UNDP 'Human Development' school - contents and criticisms..............9

3.1 Emergence and ambitions of the UNDP HD work ................................ 9

3.2 Meanings and indices of 'Human development' ..................................... 11

3.3 Are the HDRs really 'human'? - or still too economistic? .......................13

4. Functionings, capability and capabilities................................................... 14

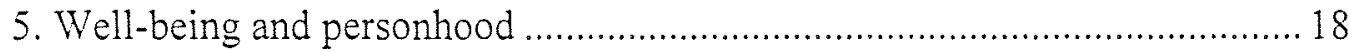

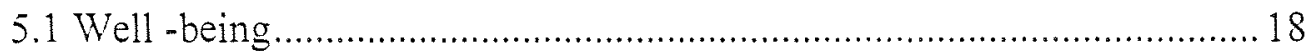

5.2 Personhood - concepts of agency and be-ing .........................................20

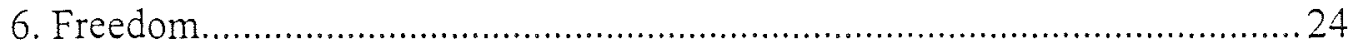

6.1 The relative importance of 'freedom' and living: capability versus

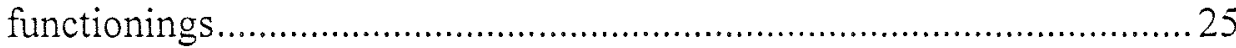

6.2 What does freedom mean? More than the range of (valued) choice........26

7. Roles and Prospects for the Capability Approach............................................28

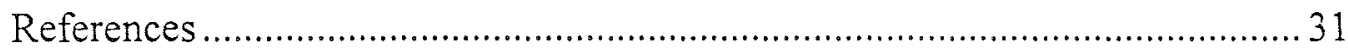





\section{A PUZZLE AND ITS POSSIBLE RESOLUTION}

Amartya Sen's work in welfare theory and the conceptualization of human development is remarkable for having combined critique of a major area of mainstream economics-welfare economics-with several further steps: elaboration and communication of the Capability Approach (CA), a humanist alternative theory which has been widely accessible and adopted, led to much empirical work and had significant policy impact. $^{2}$ It has been central to the Human Development Reports series (HDRs) launched for UNDP by Sen's close associate the late Mahbub ul Haq, and has subsequently influenced policy changes in the World Bank in the Wolfensohn era.

A puzzle arises. The capability approach has been fruitful and the HDRs are in many respects an important advance on earlier mainstream treatments of development. Yet viewed from outside economics CA seems primitive in some ways, insufficient as a theory of well-being, and hardly a theory of the 'human' in human development (HD). Amongst possible weaknesses are: its extreme emphasis on choice; obscurities in key concepts; and its emergence from a dialogue between economics and philosophy without much involvement from psychology, sociology and anthropology.

Human life is too complex to capture by a slogan that development is 'a process of enlarging human choices' (HDR 1990, p. 10, and several later HDRs). With the elaboration of the HD concept, more indicators have been added to reflect other dimensions, straining or going beyond CA's language. This limitation concerns the ambition of the claims sometimes made in $\mathrm{CA}$, and can be remedied by reducing their strength.

More fundamental are possible weaknesses in the clarity, coherence or realism of CA's other components. (Where necessary we will distinguish Sen's version by the acronym SCA.) The Capability-Functionings (C-F) conceptualization serves well to critique conventional welfare economics or the focus on GNP, but appears an insufficient basis for a whole theory of human development. Examination of the central concepts in SCA-functionings, capabilities and (positive) freedom, agency, and well-being-reveals some obscurities and question marks, as we will see in Sections 4 through 6 . General concepts cannot be perfect but there is scope here for clarification and refinement.

More fundamental still, and germane to the needed refinement, relatively little theory of being, of being human, seems to underlie SCA's proffered perspective on

\footnotetext{
${ }^{2}$ See Pressman \& Summerfield (2000) for a useful overview and an invaluable bibliography.
} 
well-being; except for a discourse of freedom, seen primarily as choice. The connection to other strands in social science is still limited, though increasing (e.g. Sen, 2000a). Even the fine volume on The Quality of Life from the UN's WIDER institute (Nussbaum \& Sen, 1993) represents very largely a conversation amongst economists and Anglo-American philosophers. This gap may mirror the insouciance of welfare economics, out of which SCA originally grew. Are psychologists, anthropologists and other disciplines still largely absent while economists build square wheels? Did SCA's very success in being adopted by UNDP help to freeze it prematurely?

I will suggest that we respond to the puzzle of CA's considerable influence yet partly problematic components by being more precise on what $\mathrm{CA}$ is useful for and for whom, and on where it does not suffice. As prelude, Section 2 specifies the contents and nature of Sen's CA project, as major intellectual basis for the UN HDRs. Section 3 then looks at the role of the HDR work in focusing and broadening attention to the purposes of development and dethroning economic growth as centrepiece. (It does not try to cover Sen's or the HDRs' policy model for human development, and for example issues of the long-run relations between macro-economic liberalism and humanized public action.) It notes the furore around the Human Development Indices, which reflected the vested intellectual interests which Sen has helped to destabilize. CA provides an advance over mainstream economic welfare criteria (MEWC) and the overvaluation of GDP. To be operational, simplified versions are needed, notably the indices, and CA's simplified versions surpass MEWC (viz. GNP, GDP, etc.). However, SCA's role is to displace MEWC, not to be a new supposedly sufficient, all-purpose conception. For it does not suffice as a theory of well-being or a conceptualization of human development. When we assess it for those purposes, we ask for more than when within the bounds and conventions of welfare economics.

A deeper criticism then than the limits of the HD indices has been the claim that the Human Development work is not adequately human. Sections 4, 5 and 6 consider

\footnotetext{
${ }^{3}$ As Lipsey (2001) observes, mainstream economic discussion is in practice utilitarian more than Paretian. Interpersonal comparisons are made openly or implicitly, typically using people's purchasingpowers as weights, via adoption of the principle of potential compensation, as for example in cost-benefit analysis: if gainers could compensate losers then a change is judged an improvement, regardless of whether compensation is actually made. Hence GDP dominates. Compensation and distribution are deemed political issues, beyond economics; if compensation is not made then it is assumed to have been politically judged as unjustified, e.g. on grounds that the rules of the game are utilitarian. This calculus informs economic policy and planning more than does Paretian welfare theory on the supposed impossibility of interpersonal comparisons etc.
} 
possible problems in Sen's concepts: of capability and functioning; well-being, agency and personhood; and freedom. His schema surpasses mainstream economics' view of human personhood by adding independent weight to freedom; and by downgrading the normative weight of 'utility' interpreted as a feeling of happiness. It provides spaces for enriching economics, and has generated a valuable corresponding research programme. But it is insufficiently refined to be the sole or predominant base for human development theory. Steps of great significance in the context of economics are less impressive in a wider context. Sen's approach remains with a thinnish conception of personhood, which can then contribute to: thin analyses of well-being; insufficient resistance to consumerism; still marginal assigned roles for sympathy and commitment to others; and a somewhat idealized conception of freedom. The criticisms apply especially to some of Sen's disciples, less sensitive to SCA's limits than is Sen himself.

The paper concludes with suggestions on where Sen's CA helps and where it is inadequate, and on additional and alternative bases for work on human development. HD theory exceeds SCA, increasingly so. We must go beyond clarifying where SCA makes its contributions, to consider how to enrich or surpass SCA to make an HD theory that is more widely adequate and can appeal to wider audiences. Ul Haq stressed (1998, pp. 228-9) that after a first phase in which the HD school met with irritated resistance and a second phase of uncritical acceptance, we require a third phase of critical evaluation. The same applies for its CA partner.

\section{THE CAPABILITY APPROACH}

Sen's capability approach includes at least components 1 to 5 below, in decreasing order of centrality, and increasingly also number 6 . Number 7 is penumbral, and numbers 8 and 9 lie outside his version.

- Component 1: A stance on information. There are many more types of information relevant in assessing welfare than the few-people's incomes, assets, and utility (levels of satisfaction or preference-fulfilment) - traditionally considered by mainstream economics. Centrally, we should also look at how people actually live, and at the freedom they have to choose how they live. In contrast, through to the $1980 \mathrm{~s}$ even the UN had defined development in terms of GDP per capita, plus from the 1980s also in terms of the capacity for its long term growth (Simonis, 1992).

- Component 2: A specific set of categories, a language. Sen added several con- 
cepts—capabilities, functionings, agency, sympathy, commitment, quality of lifeto those conventional in micro- and welfare economics: income, goods, and utility. One could list each of these concepts as a distinct component of SCA, but since they are a linked set, we treat them here as such, as a language. Functionings are various components or aspects of how a person lives. Together a set (vector, or ntuple) of functionings makes up a person's life. A person's capability (capability set) is the set of alternative functionings vectors she could attain, in other words the extent of her positive freedom. Figure 1 shows basic interrelations of these concepts. It is still a simplification; e.g., there can be feedbacks from functionings to skill-capabilities (Elson 1997 discusses work that disables).

Figure 2 highlights two parts of the conceptual system: the distinctions between potential and achievement, or capability and functioning; and between own wellbeing and the agent's fuller set of objectives. Sen argues that the fuller information we require includes not only how much personal well-being agents achieve but what they were free to achieve, and that we consider each of these cases both in terms of the agent's actual objectives and their personal well-being. 
Figure 1: From Resources through to quality of life -

Sen's Enlargement of Micro-Economics

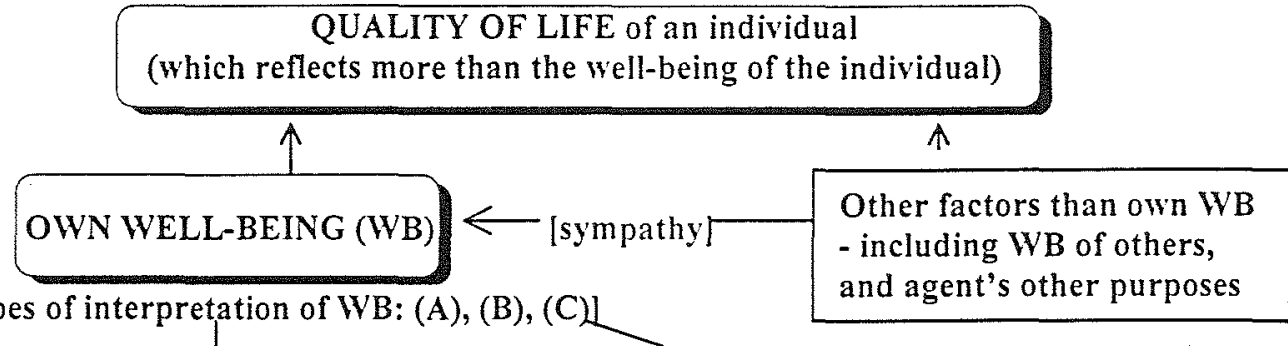

[Three fypes of interpretation of IVB: (A), (B), (C)]

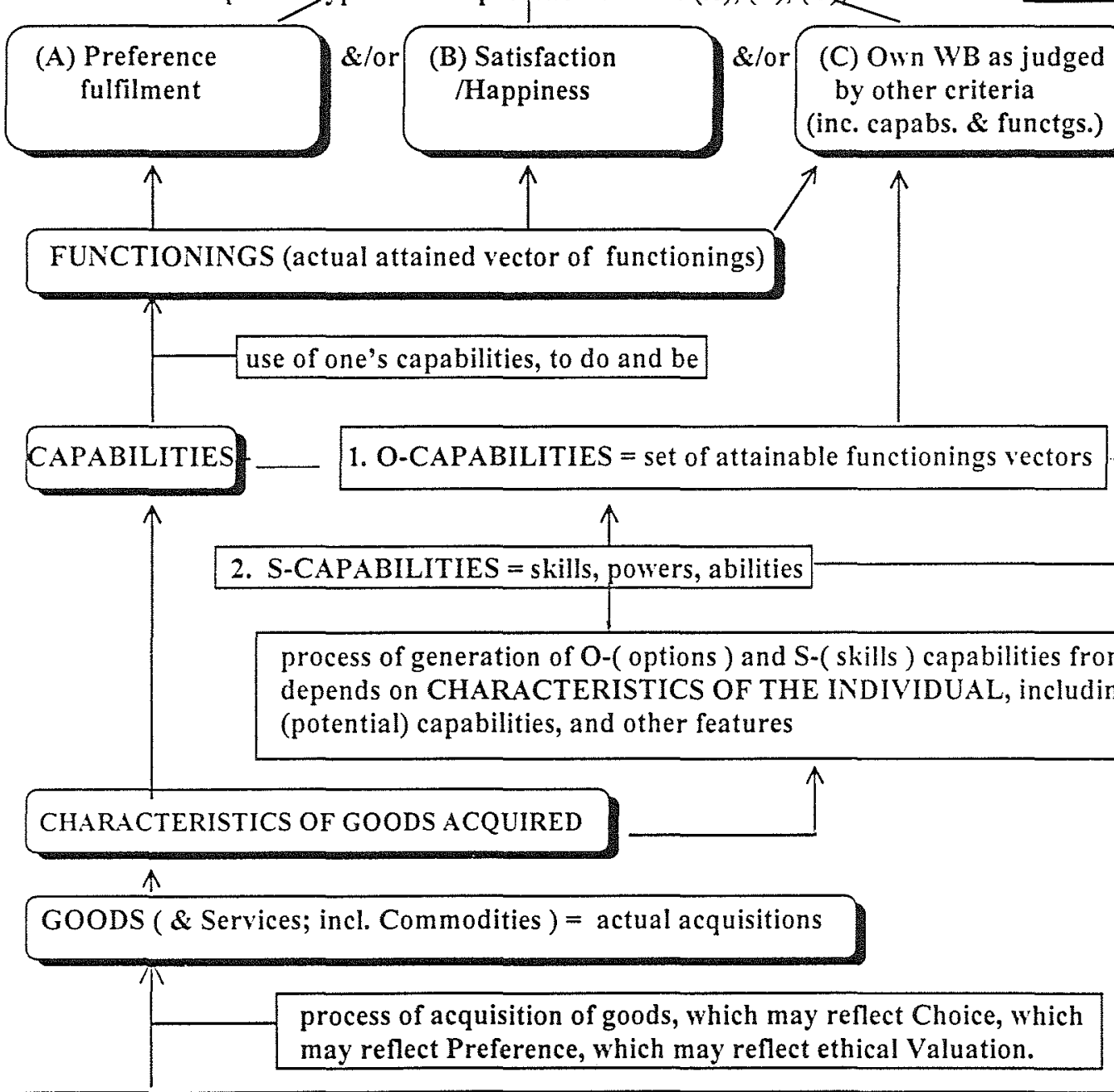

(EXCHANGE) ENTITLEMENT = set of initially attainable goods vectors; which then via actually attained income ( = real income = mainstream economics' definition of Standard of Living) leads to actual acouisition of goods

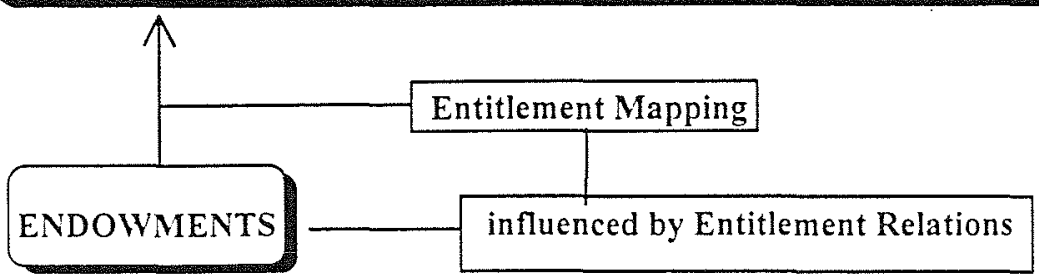




\begin{tabular}{|c|c|c|}
\hline \multicolumn{3}{|c|}{ Figure 2: Sen's categories for ranking a person's situation } \\
\hline & $\begin{array}{c}\text { In terms of an agent's } \\
\text { personal well-being }\end{array}$ & $\begin{array}{c}\text { In terms of the agent's } \\
\text { objectives }\end{array}$ \\
\hline $\begin{array}{c}\text { Actual } \\
\text { achievement }\end{array}$ & $\begin{array}{c}\text { (Own) Well-Being } \\
\text { Achievement (WBA) }\end{array}$ & $\begin{array}{c}\text { Agency Achievement } \\
\text { (AA) }\end{array}$ \\
\hline $\begin{array}{c}\text { Potential for } \\
\text { attainment }\end{array}$ & $\begin{array}{c}\text { (Own) Well-Being } \\
\text { Freedom (WBF) }\end{array}$ & $\begin{array}{c}\text { Agency Freedom } \\
\text { (AF) }\end{array}$ \\
\hline
\end{tabular}

SCA is known for its focus on well-being freedom, which is its primary category of capability. But it is also concerned ('though not with equal reach' [Sen, 1993, p. 49]) with agency freedom, the agent's ability to impact on all her values, including those for other people and those which bring no personal well-being. Income is one measure of this agency freedom (AF), albeit very imperfect. ${ }^{4}$

- Component 3: A stance concerning which levels, notably capability, have ethical priority. When prioritizing, Sen argues not for: (i) goods/commodities $(G)$, because people have different needs; nor for (ii) (solely) utilities (U)-feelings of satisfaction, or the fact of preference fulfilment-because preferences may be unconsidered or have been formed under situations of deprivation of information and of options. He advocates that we stress instead (iii) (valued) functionings (F), how people actually live, and in order to emphasize freedom especially (iv) (valued) capability $(C)$, the set of vectors of functionings a person can attain: the actual life choices the person faces. He seems to propose this priority ranking: 1 $\mathrm{C} ; 2-\mathrm{F} ; 3-\mathrm{U} ; 4-\mathrm{G}^{5}$ This normative priority to capability has limitations, and might best be interpreted as a policy rule to 'let people make their own mistakes' rather than as an evaluative rule that 'capabilities really are more valuable than functionings'. CA can already be seen as especially a policy exercise, since it has diverged from U, people's own utility measures of welfare. We can therefore distinguish as a separable fourth component:

- Component 4: Priority to capability/capabilities as a policy rule. Capability (WBF) is here seen as an appropriate measure of advantage rather than of well-being

\footnotetext{
${ }^{4}$ In Figure 1, agency in the ordinary sense is seen in the acquisition and use of income and goods, and the use of capabilities. In the sense of pursuit of an agent's objectives it is reflected both in the box 'Own WB', insofar as own well-being falls within the objectives, and the box 'Other factors than own WB', insofar as the agent has other objectives.

${ }^{5}$ See e.g. Sen (1999b): pp. 3, 75-6. Insofar as CA recognizes more than one relevant level, decisionmaking requires complex plural rules; see component 6 .
} 
(WBA), though it might contribute to well-being. In contrast, Functionings much more concern well-being. The very term 'functioning' matches 'being' better than does 'capability'. Next come a series of competing-cum-complementary approaches to determining how and which capabilities should be prioritized.

- Component 5: A principle akin to consumer sovereignty, namely that priority capabilities are those which 'people have reason to value' (see e.g. HDR 1998, p.40). Having distanced itself from felt utility and preference fulfilment, SCA re-admits preferences here, but with a stress on informed and educated preferences about capabilities. Since it works at a policy level with a capability currency, how SCA operationalizes this idea is not obvious; hence the addition of component 6 .

- Component 6: Public procedures for prioritizing and threshold-setting. Alkire notes that SCA incorporates a stress on public discussion and decision procedures for prioritizing which and whose capabilities. This is for where Sen's criterion of 'whatever people have reason to value' in individual deliberations does not suffice; and acts as prelude, partner and postlude to it. Nussbaum also stresses such procedures, in specifying, interpreting and applying constitutional rights in a polity, and when working beyond them.

- Component 7: In practice, Sen and the HDRs use also notions of basic capabilities (basic for survival or dignity) and required thresholds (e.g. Anand \& Sen, 2000, p. 85; or in the HDRs' specification of equity). While these notions are ones most people find reason to value, component 8 guards against those cases where agents' reason instead leads to behaviour damaging to the agents or to others. Prioritization here remains however largely inexplicit and deliberately incomplete in Sen, who has eschewed a systematized list with universal pretensions. Component 7 reduces to component 6 if 'basic' is only a label for the priorities chosen through component 6 's procedures within a particular political community.

- Component 8 is an extended version of Component 7: A formal list of priority capabilities. This is explicit and emphatic in Nussbaum and some other authors, and in the Declaration of Human Rights. For Nussbaum her list provides a basis for universal declarations of rights, whose precise local meanings remain however to be formulated, and for national constitutionally entrenched rights. Component 8 can thus be part of a particular sort of constrained public prioritization procedure. Sen's 
recent partial convergence with the human rights approach may bring him closer to it.

- Component 9 is a monotheistic, stronger version of component 3, not part of SCA but quite widespread in HD literature: a proposal that we should look only at the capability level (e.g. 'development is the expansion of capabilities'). This slogan does not suffice as a theory of welfare or as a policy rule.

\subsection{Real abilities, real humans, real development ?}

With the categories of functionings and capabilities, and of basic requirements, Sen moves towards a picture of human life which could give a fitter welfare economics. He provides a system which has a careful philosophical basis, and that accomodates, justifies and links a wide range of concerns, far wider than those subsumable under the economics category of real income (Sen, 2000b). It thus integrates the earlier work on social indicators, basic needs and poverty assessment, and stimulates much additional work (see e.g. Alkire, Comim \& Qizilbash, 2002). Sen retains though an abstracted conception of choice. Abstraction from incidentals is necessary; abstraction from essentials is disastrous. Does SCA abstract from essentials? Does it retain restricted disciplinary habits? And if so, can it be reformed?

The content and assumptions of Sen's work reflect that he is engaged in a conversation with economists and analytic philosophers, as a member of both groups. He proceeds in ways which are accessible and credible to mainstream economists, his original and main reference group, and retains most of their assumptions and style; thus he omits for example much substantive discussion of the content of processes of choice.

This style can feel abstract and empty to many from other disciplines and professions. Its theory of well-being still rests on the basis of relatively little explicit consideration of being; nor, as a result, has it an explicit and elaborated theory of the good. There is a contrast here in both respects with Nussbaum. Her CA is richer and even so is incomplete compared to material from psychology about what brings people satisfactions. The HDRs too have, as we will see, a fuller conception of being than do Sen's formal writings.

Sen's approach has wide appeal, however, since it seems a feasible way forward both to some mainstream economists and some critics. It offers a clear improvement, with more of a theory of being than in mainstream economics but not so much as to en- 
danger the device of aggregate indices or to lose the economist audience. Further, while the formal core of his approach is conceived and expressed in the stripped-down abstract style, Sen uses richer cases for motivation, illustration, testing and application. He talks about specific people, real or imagined: he adds the philosopher's imaginable case and the administrator's real case to the economist's individual depleted of all personality other than appetite, volition and powers of calculation (Gasper, 2000a; van Staveren, 2001).

Sen has consciously stayed apart from the more substantive formulations of human potentials, requirements and personality by basic human needs theorists and Nussbaum. Those perhaps cannot be formalized in the way's required by his style, but he also fears essentialism and cultural parochialism. However the possible price for distance from more substantive work on the meaning, contents and requirements of human-as opposed to human resource-development is a series of limitations, as claimed by various authors:

1. Sen's concepts of functioning, capability and capabilities are sometimes obscure.

2. His conceptions of well-being and agency are problematic and partake of some weaknesses of utilitarian psychology; while his conception of personhood is very incomplete.

3. His conception of freedom seems too focused on range of (valued) choice, and neglectful of other aspects of being and need.

We consider these criticisms in turn in sections 4 to 6 . Before that, Section 3 presents the UN's Human Development approach which CA underpins and which has effectively challenged mainstream economic criteria, and looks at the objection that it is still not sufficiently human.

\section{THE UNDP 'HUMAN DEVELOPMENT' SCHOOL - CONTENTS AND CRITICISMS}

\subsection{Emergence and ambitions of the UNDP HD work}

The 1990s Human Development Reports have provided a channel for alternative development thinking, through the United Nations system but with an autonomous voice. They have a global perspective not only a focus on 'the South', unlike in the World Bank's so-called World Development Reports. They have gone beyond the 1970s responses to the limits to trickledown from economic growth, by arguing that measures like directly investing to meet basic needs are not only growth-compatible but 
can promote growth. Here they built on the perception of the centrality of 'human capital' in growth and related lessons from the East Asian success stories. Building also from perceptions of low or declining quality of life in some rich or fast growing countries (ul Haq, 1998, Ch.3), they redefined human development as improvement in human well-being, and thus as more than human resource development, the building of human capital to support economic growth. People are not just the principal means but, even more important, the principal ends of development (Anand \& Sen, 2000). Economic growth must be seen as a means towards human development rather than human development as being for economic growth.

The adjective 'human' in 'Human Development' thus conveys the suggestion that earlier economic development was not human-centred and that 'development' was in practice inadequately conceived and operationalized as economic growth. GNP was never suited to be a measure of well-being. It was designed to measure monetized activity, much of which represents lack of or loss of well-being; it excludes many other aspects of or influences on well-being (household work, family life, leisure, freedom, etc.; HDR 1996, pp. 56-7); and it can conceal extreme deprivation for large parts of the population. Development should be reconceived as about decent human lives, not in terms of per capita GNP.

Secondarily, the HD label evokes the 'Development of Humans'-Human Resource Development (HRD) and its functionality for economic advance-in other words a concern for 'human capital', but now seen in a broader way. When Dreze \& Sen (1995) for example stress the significance of basic education for economic growth in India, even though returns are sometimes long delayed and even if India has plenty of qualified people for most immediate functions, they show how basic education also affects fundamental areas in state-society relations-including the ability to discipline government and other power centres-and the status of women, and hence much else, such as fertility patterns.

At the same time, the HDRs have not downplayed economic growth. Contrary to the impression given in for example Ravallion (1997), they have taken East Asia as their main model, not Kerala or pre-1977 Sri Lanka. The 1996 HDR held that while economic growth is neither sufficient for HD improvement nor necessary for it the 1980s and early 90s saw major HD improvements without fast or even any economic growth in many countries); yet sustained rapid HD both requires and is promoted by fast economic growth, amongst other requirements, and this combination is the ideal. 


\subsection{Meanings and indices of 'Human development'}

Development means widening the 'range of human choices', said Arthur Lewis in 1955 (cited by HDR 1996, p.46). Sen's capability approach and in turn the HDRs have adopted this conception: 'Human development can be expressed as a process of enlarging people's choices' (HDR 1996, p. 49; HDR 2000, p. 17). However, some options are undesired (like the option to become HIV positive) and some are insignificant (a thousandth variety of biscuits, say). Valued options are the relevant ones, stress the HDRs and Sen, who speak of 'people's capabilities to lead the lives they value' (HDR 1996, p. 49), which includes avoidance of negatively valued options. This is a liberal position, which emphasises (individual) freedom and people's own priorities, not only basic needs. It hopes those priorities are tolerable.

Further qualifiers arise. The HD concept has expanded to encompass several dimensions (e.g. HDR 1996, pp. 55-6). In addition to (1) empowerment, the expansion of capabilities plus participation, are listed: (2) equity (in basic capabilities and opportunities; i.e. everyone should have at least a certain minimum level of opportunities); (3) sustainability (of 'people's opportunities to freely exercise their basic capabilities', loc. cit.); (4) community membership, belonging; and (5) security. The concept has progressed beyond the soundbite phrase about enlarging people's choices; and, in its references to participation, community membership and security, now says more about which capabilities are central.

To operationalize such a conception, UNDP essayed a series of measures to go beyond GDP per capita. It valuably presents many indicators rather than glorifying one (see e.g. UNDP HDRO, 1997). The most prominent, the Human Development Index, (HDI) was primarily originated by Sen and is based on: 1. mean longevity, 2. mean schooling and literacy, and 3. GDP/capita adjusted to reflect purchasing power. It is meant as an indicator of people's opportunities for a good life. Each of the three components is meant to form a proxy measure for a range of areas of choice. ${ }^{6}$

While accepting that income is only a means, the HDI uses GDP/capita as proxy for most other capabilities beyond survival, education and what those directly reflect (Anand \& Sen, 2000). This is problematic. It also helped Ravallion and others to argue that such a high correlation exists between HDI and GDP/capita rankings that the HDI

\footnotetext{
${ }^{6}$ Since longevity and years in formal schooling do not directly measure choice, to Apthorpe HDI remains 'a measure not of human development, not of human choice, but of human capital' (1997, p. 24).
} 
is superfluous. But even if GDP/capita (adjusted for price levels) were a good development indicator in $90 \%$ of cases, one could not be satisfied, just as a good doctor would not decide from a medical indicator which is invalid in $10 \%$ of cases and/or fails for some very important cases (cf. Brazil, Pakistan). Nor, even if there were perfect correlation-which is far from the case (Anand \& Sen, 2000; UNDP HDRO, 1997)-could the conclusion be drawn that we can stick to GDP/capita. For the HDI only claims to be a simple indicator (not the concept itself) of part of the UNDP concept of human development, the part that stresses possession of valued options. ${ }^{7}$ The several other dimensions of well-being may well not be positively correlated with GDP/capita. (See e.g. Apthorpe, 1997, on Bhutan.)

Another charge levelled at the HDI was of unnecessary and misleading aggregation. But aggregation is essential to produce league tables, and these are required to capture attention-by showing the marked divergence in many cases of HDI ranking from GDP/capita ranking - and to thus focus thought on the inadequacies of GNP or GDP as a welfare measure and policy target (Streeten, 1995; Sen, 1999a). In all this the HDR work has succeeded and had a major influence in the enrichment of development policy debate and planning during the 1990s. The aggregation weights and value choices it uses are explicit and transparent (see the HDR technical appendices; and e.g. Anand \& Sen, 2000), whereas the price weights which are used in market measures and often to make valuations in public policy are too often read as somehow representing no value choices. The HDR work makes the valuation and prioritization more open, and makes it clear that indicators are only indicators. No one has proposed HDI as a sufficient indicator for policy, unlike sometimes in the case of GNP. HDI serves instead mainly to weaken the primacy given to GNP. The summary indexes are not the core of the HD approach, but a counter to GNP and its associated presumptions and blindnesses. In a two-tier approach they are the lesser part, compared to the wealth of information presented on varied aspects of human development (Anand \& Sen, 2000); but they have stimulated work on better measures and disseminated HD concepts and criteria. Sen originally disagreed with Mahbub ul Haq's judgements on the strategy and tactics of producing inevitably simplified indexes. Now he warmly acknowledges ul Haq's wisdom here (Sen, 1999a \& 2000b).

\footnotetext{
${ }^{7} \mathrm{An}$ index is a measure derived as a summary of component measures. An indicator is an (in general) imperfect, proxy measure of some phenomenon. The HDI is both an index and an indicator.
} 


\subsection{Are the HDRs really 'human'? - or still too economistic?}

Mainstream economics' theory of well-being is not based on any explicit theory of, and evidence on, being. Indeed it does not deal in recognisable real human beings. Its conception of welfare is focused on the investor and the consumer of commodities: the whole of life viewed as a stock exchange or supermarket. It is weak even on the satisfactions from work and typically presumes, like a capitalist employer, that work is always a cost. In his entitlement and capability approaches, Sen has helped to extend and transform that welfare conception, to include the ranges of valued options which people have and the content of their lives. This step rests on a richer conception of personhood, including a central significance for freedom and a rejection of a single psychic currency of utility. Some economists overlook this structure in Sen's corpus. ${ }^{8}$ His Human Development work gains a compass and robustness from his underlying reconstruction of welfare theory, which in turn derives rationale and guidance from the rethinking of values and personhood in his philosophical work.

Does this picture of human welfare, enriched as seen by the standards of economics, suffice for our conception of human development ? Apthorpe, a well-known anthropological voice in development studies, queries the understanding of 'human' and 'social' shown in the UNDP work. He argued that the global HD Reports have been dominated by economists-Sen, ul Haq, Streeten, Jolly, Stewart, Anand and others-who have (again) considered themselves omnicompetent, because now 'human' too. In his view this reflects an economics-dominated world which the HDR economists otherwise sometimes criticize. While use of the term 'human' gives a warm feeling, it can divert from social and political analyses. Global generalities break down when we look at national and local situations with their specific institutions, groups and cultures. The 'social indicators' used are demographic and sectoral, never about social institutions, social structures, or groups' own social categories (Apthorpe, 1997, p. 27). He hoped the new wave of national HDRs would get closer to these realities, and gave suggestions for richer and more self-aware styles of description: 'To merit further credibility they will.. have to be much stronger on social and economic and cultural description than are the present HDRs: traders must be brought in as well as trade, farmers as well as farms, educators as

\footnotetext{
${ }^{8}$ See for example the commentaries on Sen's work by three leading Indian economists (Prabhat Patnaik, Tapas Majumdar and Kaushik Basu) in Economic and Political Weekly (Mumbai; November 7 and December 12, 1998). In contrast, Pranab Bardhan (November 7) and A.K. Bagchi (December 5) present the connections.
} 
well as education...' (1997, p. 23). Given the HDRs' commitment to economic growth, and their abstracted sense of 'human', some critics see them as in practice a school of humaner economic development, rather than of development of and by humans.

Let us examine the attention to human be-ing in the underlying capability approach created by Sen. It represents an increase in attention compared to mainstream economics, but is it enough? Enough for what?

\section{FUNCTIONINGS, CAPABILITY AND CAPABILITIES}

Let us start with the term 'capability', the chosen banner. It marks a family of concepts central to practically oriented discussion of ethics and politics. The philosopher Onora O'Neill for example makes intensive, and largely interchangeable, use of the terms 'capacities' and 'capabilities' in her construction of a realistically grounded modern cosmopolitan ethic (O'Neill, 1996, 2000). 'Capability' here generally has an everyday meaning: capacity, skill, ability, aptitude; we can call this S-capability (S for skill and substantive; Gasper, 1997). It is the sense that O'Neill seems to rely on when she talks of 'capabilities for action', 'capacities to reason', 'capacities to comply', commercial, cognitive and social capacities, and so on.

Sen has taken a more abstract meaning of capability: the set of life-paths attainable for a given person. ${ }^{9}$ We can call it $O$-capability ( $O$ for options and opportunities; 'options' seems aptest, and suitably economic; the usage is also akin to 'military capability'). But Sen still trades on the-appealing, more human-connotations of Scapability, perhaps because he aims to also communicate to and influence wider audiences. He dropped the label 'capabilities approach' in favour of 'capability approach', but still writes of 'capabilities' in more everyday ways, and when referring to sub-sets or particular attainable functionings in the capability set, or to the options to attain them.

The word 'capability' comes in routine CA and HDR use to cover any specific thing a person can do, be or have, and thereby loses distinctiveness. Thus health is called both a functioning and a [O-] capability (an attainable functioning). The 1999 HDR designates 'Caring labour...a capability in itself' (p.7) and an 'essential capability' (p.77). Why would one not call caring labour an essential functioning or activity, or

\footnotetext{
${ }^{9}$ Sometimes he restricts himself to favourably valued capabilities. Alkire (2002) remarks that this is inconsistent with everyday usage and leaves no term for describing the non-valued or disvalued.
} 
just essential? Perhaps because 'capability' brings connotations of skill, learning, importance, and of need for protection and promotion.

We can then have blurring of two types of boundary: between options and capacities, $\mathrm{O}$ - and S-capabilities; and between capabilities and functionings. The result seems to be some confusing or even confused usage by others, including in the HDRs and by sympathizers. For example:

- The $1996 \mathrm{HDR}$ speaks of 'such capabilities as health, knowledge, self-respect' (p.49; also p.54); and of 'health and nutrition. Human development sees these capabilities as ends in themselves' (p.55). In normal language each of these things is a functioning (or, in the case of knowledge, an S-capability), not an opportunity sets, the HDRs' own definition of capability. The passage seems clearer if we write: 'such capabilities as the options to have health, knowledge [etc.]', even though it no longer makes sense in terms of the 'opportunity set' definition.

- Similarly, the 2000 HDR defines the [O-]capability (set) of a person, and in the next sentence switches to 'capabilities' without further explanation, so one would presume these are just the plural, referring to many people (p.17); but the study subsequently uses 'capabilities' to refer to diverse aspects of a given person's life. ${ }^{10}$

- 'Human development is the process of enlarging people's choices, by expanding human functionings and capabilities', defines the HDR 2000 (p.17). But expansion of Ocapabilities is simply another description of enlargement of choices, not a means or path towards that, so the reference to capabilities is tautologous. It would make sense in terms of expanded S-capabilities, but then diverge from the HDR's own definition. ${ }^{11}$

The HDR's founder himself repeatedly implicitedly used the S- versus Ocapability distinction. He stressed 'The contrast between women's capabilities and opportunities' and looked forward to 'a fundamental change in the very model of development so that human capabilities are built up and human opportunities enlarged' (ul Haq, 1998, pp. 208, 212).

In her capabilities (sic) theory, Martha Nussbaum has a more explicit and rich picture of human beings, and treats S-capabilities and further aspects of human person-

${ }^{10}$ Elsewhere it seems to talk of S-capabilities: 'nutrition, education, health care and socialization help build the human capabilities on which a person's human development-and society's-will depend' (HDR 2000, p.76). Nutrition here builds [S- ?] capabilities and is presumably a process, while the 1996 HDR (cited above) treated it as a state of affairs and an [O-] capability.

${ }^{11}$ Note also: (a) Elson (1997:57): 'human capabilities which are activities through which people can express themselves'. (b) Harriss-White (1995:138): 'because nutrition is a means to a variety of ends - in Sen's words it is a capability'; although nutrition in the sense of being well/better-nourished is a means to various ends it is neither an O-capability set nor an S-capability. 
ality (e.g. Nussbaum, 2000). But she also distinguishes O-capabilities, which she calls 'external' capabilities; and notes too that S-capabilities are derived from 'basic' (or better, 'potential / P-') capabilities, through training and learning. ${ }^{12}$ This trio of concepts, while imperfect, is superior to using a single label for diverse notions.

Sen has not followed this lead and refined his terminology. To change terms whose pitfalls one is familiar with and master of may seem unnecessary and disruptive. The O-capability concept has the merit of taking into account constraints and opportunities in the environment as well as personal powers. Further, the obscurities have not prevented valuable work with operational measures of capability (whether variants of O- or S-) in the past decade. ${ }^{13}$ But the weakly refined terminology derives from an insufficiently refined picture of persons, and leads then not only to confused and confusing usages: it perpetuates the crude picture of persons. And it seems remediable.

The 'capability' concept rests on the concept of 'functioning'. That spans not just many spheres of life, it covers widely different types of aspect. 'Functioning' sounds like 'activity': doing, being, operating. But it also covers outcomes of the activity (including of non-conscious activities) and in fact a series of stages. 'Functionings' can mean a) an achieved state (like being without malaria), b) a conscious action to achieve the state (taking a malaria pill), c) internal bodily processes/activities (converting the pill to guard against malaria), and d) activities consequent to the achieved state (like living longer). ${ }^{14}$ Further, the achieved state can include the state of having a capability! Even 'utility' can be deemed a valuable functioning, a point long adopted by Sen to allow mental states as a family of types of functioning. The functionings space also spans all time periods: so the language of functionings covers both 1 . health now and 2. a long life. Extending Figure 1, we can draw Figure 3 as one scenario, to hint at the forest of stages and types of 'functioning' and of moments of choice and use of 'capabilities'.

\footnotetext{
${ }^{12}$ Nussbaum's own labels are unsatisfactory. For S-capability she uses 'internal capability', but potentials are also internal. 'Basic' is similarly imprecise and possibly misleading, for one should know basic to what.

${ }^{13}$ See Dreze \& Sen (1995) as an example, and Sen (1999b) and Robeyns (2000) for surveys. Adequacy will depend on the purpose; e.g. for Nussbaum's agenda of identifying basic constitutional principles the need for precise measurement might be less.

${ }^{14}$ This ambiguity or plurality is reflected in the label chosen, 'functioning'. In mathematics a function is a relationship between inputs/activities and outputs, a mapping; in administration a function is an activity or set of activities towards specified outputs; and in everyday language it is the purpose fulfilled, the outputs achieved, while 'functioning' means activity or to adequately fulfil a role.
} 
Given the ambiguity of both 'capability' and the term on which it relies, 'functioning', and the ample spread of the latter, the distinction between the two is sometimes lost. ${ }^{15}$ 'Functionings' also sounds less appealing, less morally nourishing, than 'capabilities', so some users drift towards the latter; or when in doubt, mention both. ${ }^{16}$

GOODS

e.g. malaria pill

Figure 3: Endless Pathways of Functioning and Capability
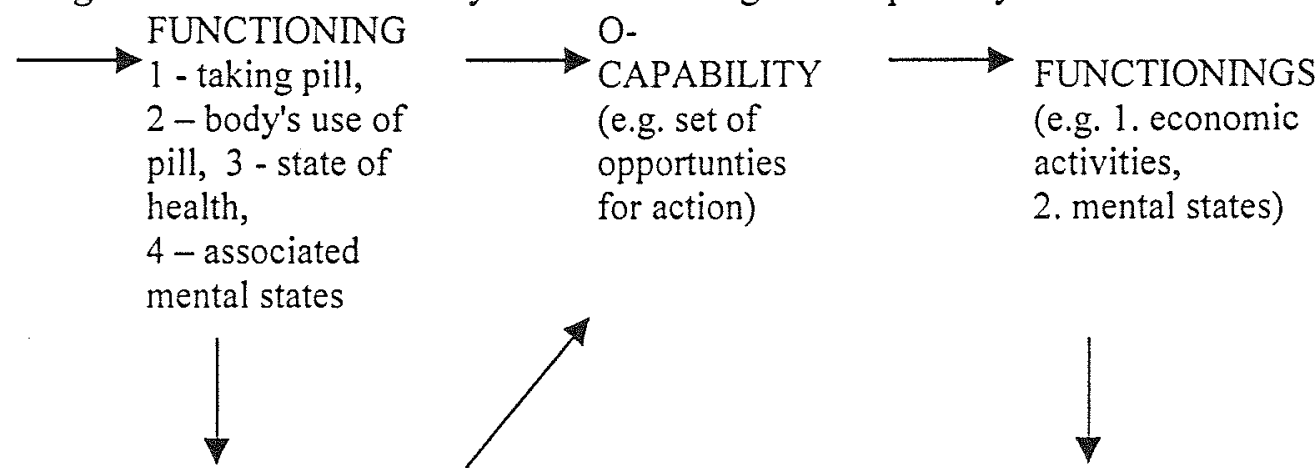

$S-$

FUNCTION-
ING ( 1 - con-
sumption;

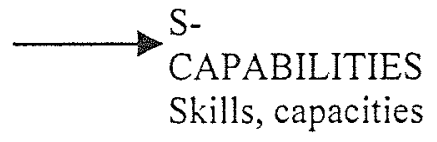

Skills, capacities

ENTITLEMENTS

2 - associated

mental states)
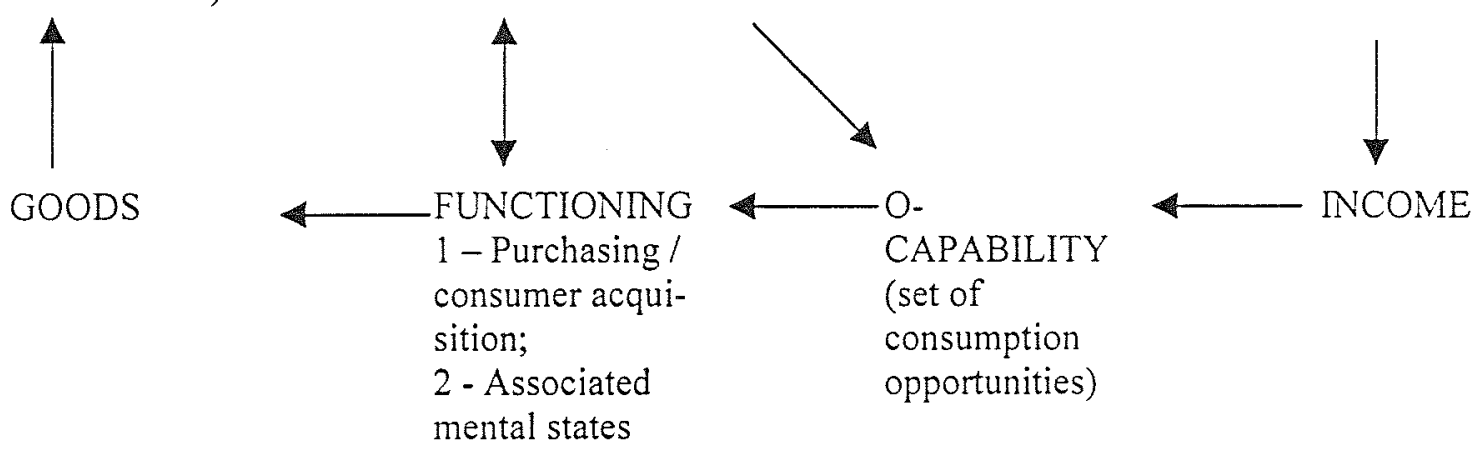

While Sen's $C$ and $F$ terms are vague, they point to useful contrasts: with income and utility, and between themselves. The $C$ versus $F$ contrast is vital in a liberal philosophy where people have rights to opportunities and to then make their own choices, mistaken or not, self-oriented or not. Cohen (1993) argued that coverage of a range of possible stages between goods/characteristics and utility-including opportunities, activities and various levels of outcomes-by just two terms fits this perspective. Most of life is placed under two heads: attainable activities or states, and personal

\footnotetext{
${ }^{15}$ In addition when Sen (1999b:75) and HDR 2000 (p.17) define functionings as the valuable things that a person 'is actually able to do' / 'can do' (italics added), they are referring to potential functionings, parts of the various elements of the capability set, and they can equally be read as defining capability.

${ }^{16}$ This might explain the tautologous reference to capabilities that we saw in the HDR 2000's definition of human development.
} 
choices as to whether to use those opportunities. Sen has not felt the need to be more specific here; instead he adds the dimension of 'well-being v. agency', which we consider later. His categories tell us to look in certain directions, not only those of mainstream economics; but they do not provide much further guidance. The discursive space which they help open up seems to require more elaboration. For a theory of human development-for understanding and action, not only evaluative accounting-do we not need to say more about 'human', human action, and personhood (Douglas \& Ney, 1998)?

\section{WELL-BEING AND PERSONHOOD}

Sen noted that 'the utilitarian view of the person' presumes that well-being means happiness or preference fulfilment, and that it ignores non self-interest objectives and freedom considerations (1987, p. 58ff). He has offered an alternative that seeks to remedy these limitations including by attention to motives of sympathy and commitment and to freedom as well as, indeed ahead of, achievement. But he has conducted this exercise as a patching operation on what remains in part, in Talcott Parsons' sense, an utilitarian conception of persons and society (Parsons, 1937). ${ }^{17}$ That conception also included the following: (i) society is a sum of individuals; Sen seems to retain this; (ii) individuals make choices: he retains this preoccupation, but with a focus on objective outcomes; (iii) ... and individuals experience and choose according to private utility...: he goes clearly beyond this, but perhaps not comprehensively; (iv) ... which they (andior the State at an aggregate level) will try to maximize: Sen rejected this last element as inadequate. Here we look at the other three elements.

\section{$5.1 \quad$ Well-being}

'Well-being' might mean any evaluation of a person's situation, or, more fittingly, any such evaluation which is focused on the person's 'being'. Sen's version of CA has an intermediately complex concept of well-being: the fulfilment of whatever own-functionings 'people have reason to value', and especially the freedom to allow this. $^{18}$

\footnotetext{
${ }^{17}$ Thus Nussbaum (2000), Gore (1997) and others reject Sen's 'agency'-'well-being' categorization: they share the concern for agency, but feel his concept of 'well-being' retains too much utilitarian baggage.

${ }^{18}$ See Sumner (1996) for a probing examination of Sen's formulation by a philosopher.
} 
Some critics doubt whether SCA diverges enough from mainstream economics to distance itself from consumerism: the unending addictive quest for fulfilment - or at least novelty and distraction-through commodities (Cameron, 2000). Which pleasures and values enrich and sustain one, and others? And which disable? Argyle (1987) found, for example, in Britain that fulfilling work and quality of family life were key determinants of felt well-being. Yet if say quality of family life is unrelated to per capita income or negatively related to it, at least in some cases or some stages or for some styles of income growth, then focus on income as the measure of well-being can severely mislead. We can expect that if the HDRs do not measure fulfilling work and quality of family life, which could be difficult, they will not provide strong measures of well-being. The 1998 HDR reported that 'Many opinion surveys show that people place a higher value on community and family life than on acquiring material possessions' (pp.12-13), yet did not flinch at the prospect that industrial countries' consumption might increase four- to five-fold over the next half century (p.8). It implicitly held that there is no necessary link from absorption in material possessions to decline in the higher valued areas.

A hardly differentiated utility category may still sometimes lurk, even entitled 'well-being', in Sen's system: in the contrast between 'sympathy' (where others' benefit brings one feelings of well-being) and 'commitment' (where one supports their benefit despite ro such impact). Sen refers briefly to 'The variety of motivations that we have reason to accommodate' (1999, p. 272), but makes no regular employment of differentiations within well-being, for example between pleasure and happiness, or types of happiness (Giri, 2000), or Scitovsky's categories of 'comfort' and 'pleasure'. Scitovsky's work on consumption and habituation receives no mention in the thousand or so references in Development as Freedom; nor for example does Erich Fromm's analysis of 'having' versus 'being'.

The concept of well-being remains underdeveloped here because the theory of personhood is underdeveloped too. And so there is no close attention to other mental states (unconscious as well as conscious) either. Sympathy and commitment are not examined deeply. While sympathy means to feel with or for another, Sen restricts the term's scope to exclude ('commitment') cases where one has a concern but is not directly (dis)comforted - as if such concerns were not feelings too and there were only one currency of feelings (namely, utility). 


\subsection{Personhood - concepts of agency and be-ing}

As part of his critique of utilitarianism, Sen has added 'agency' analysis to, in his terms, 'well-being' analysis. Agency objectives and personal 'well-being' objectives are conceived as largely overlapping sets, but significantly non-identical: one wants some things other than one's own pleasure and comfort, and does not want all the things that would bring them. A person's quality of life is then defined as a function of not only well-being (WBA and WBF), but also of agency freedom and achievement. This is one version of what Durkheim called Homo duplex (Douglas \& Ney, 1998, p.46). So as we saw, in this conception the fulfilment of objectives other than for one's own functionings appears not as part of well-being; instead it is part of 'quality of life'.

In principle, agency analysis can broaden the concept of [O-] capability. A person's O-capability was defined as the set of attainable functionings vectors for that person; the category of functioning was the actor's own functioning. The concept of Agency Freedom, rather than Well-Being Freedom, goes further. Its concrete measurement can be difficult though, as seen in the HDI's use of the flawed proxy of income per capita.

A deeper concern is that SCA's conception of agency, like that of well-being, seems thin. More must be said about agency than that people want things other than personal comfort. Sen does stress the centrality of agency for effective change strategies and the felt quality of life: people are not merely patients for treatment but motivated actors whose actions make a difference (e.g. 1999, p.19 and Ch.8). But he acknowledges that his exposure to sociology, anthropology, psychology and other social sciences lacks depth compared to his engagement with philosophy (see e.g. his interview in Swedberg, 1990), and he does not tackle the content of agency. Here, in van Staveren's formulation, actors require a series of what she calls moral capabilities (part of S-capabilities): to be able to interact with others, and to form purposes and then care about, commit to and act on these, and to deliberate about the tensions and balancing between different incommensurable values.

Central to Sen's view is the choosing, reasoning individual, but with little further specified content of being human (cf. Bauman, 1988). Though he refers also to rule-led behaviour and the constraints set by socially constructed meaning systems, and to individuals within families, the dominant impression is of people as choosers, their 
formation only lightly treated, rather than as actors more broadly. ${ }^{19}$ Yet a way of life is more than a set of private choices; and personality and identity have a psychic and social grounding.

Two important foci in such debate have concerned: Is the CA overly individualistic or can it grasp and employ the idea of 'social exclusion'? Should CA explicitly specify central human capabilities? We consider these in turn.

Some social scientist critics see the focus on the generalized 'human' as a way to avoid talking about the situated social. C.T. Kurien has argued that the lack of a social framework in Sen's analysis-his abstracted individualism-diverts him into trying to upgrade the details of mainstream economics and renders his work unreliable as policy advice. Perhaps reacting to such criticisms, Sen's new study of 'social exclusion' reserves that term for the relational (i.e. concerning the relations between people) causes and processes from which some people suffer deprivations (2000a, p. 9). Unlike with functionings, here he marks a process-result distinction by differentiated labels. He withholds the exclusion term from other cases even though they involve the, vital, result of exclusion from full membership of a community. Or is it vital? For Sen it still appears to have a secondary status. He focuses on impacts, if any, of relational processes and community membership or exclusion therefrom, upon the range of valued choices open to an individual. Community membership is taken as instrumental not central to being. ${ }^{20}$

Somewhat in contrast, the market mechanism receives the accolade of 'a basic arrangement through which people can interact with each other, and undertake mutually advantageous activities. Thus seen it is very hard to appreciate how any reasonable critic could be against the market mechanism in general' (Sen, 2000a, p. 33). Yet while markets have massive virtues, the broad objections to them are no mystery. Membership in markets is defined by the amount of exchangeable resources or money one has or can access as credit; thus markets exclude. Further, commoditization dehumanizes in

\footnotetext{
${ }^{19}$ This perspective is strong in the 1998 HDR on consumption, for example in its thesis that 'the key' to 'enabling the consumer to decide which choices are best' is information (p.43; emphasis added). Anand and Sen wrote a lead concept paper for this HDR. In Swedberg (1990), Sen outlined more complex ideas of personhood as a composite of identities from different group memberships, which he planned to explore in a book on Rationality and Society.

${ }^{20}$ In Doyal \& Gough's theory of need, ability to fully participate as a member of one's society is a key integrative criterion for judging the quality of human agency. They and Gough \& Thomas (1994) offer a carefully theorized and tested adaptation of SCA terms, and a larger theoretical and empirical framework. See Gasper (1996) for a discussion.
} 
various ways; and it generates concentrations of wealth which may come to dominate all spheres of life.

Even if one keeps to an instrumental view of community, one might hold that the link between inclusion and well-being is so major and universal that community (and/or family) membership deserves separate mention as a dimension of human development, as granted now in the HDRs. A further ground could be if not mentioning a vital instrument brings danger of its neglect. Strictly speaking however, separate mention implies more than instrumental status: that community membership (or affiliation, in Nussbaum's more flexible and nuanced formulation) is a universal good in itself, not just a handy instrument for giving individuals more valued options. People are seen as requiring affiliation. Perhaps this good can be described as a valued option, but if people without affiliation are harmed to such an extent as to no longer meet a conception of decent humanity, then to call it an option becomes misleading. However Sen eschews explicit listing of features as core requirements, other than physical subsistence and, one may say, freedom.

The CA is ethically individualistic in the sense that it assesses states of affairs only with respect to properties of individuals, notes Gore (1997). He advocates that since the content, meaning, and value of many functionings of persons depends on the cultural context (systems of language, norms, institutions), those systems have intrinsic value and one should not take isolated aspects of persons as the only objects of value. Since we should reject methodological individualism, so we should reject ethical individualism, runs the argument. Robeyns (2000) denies CA is methodologically or ontologically individualistic. But it is in any case not clear that rejection of methodological individualism obliges rejection of ethical individualism; or even that SCA is exclusively ethically individualistic. ${ }^{21}$ Whether SCA is or is not, should or should not be, any of these things, the underlying concern that emerges as one ponders such issues is rather that it uses a thin picture of persons (cf. Stevens, 1996), and so gives a thin and often insufficient basis for a theory of well-being and human development. This is a separate issue too from the defence of reason, secularism and cross-cultural learning, where Sen (e.g. 1999c) performs doughty and insightful service, showing that much of

\footnotetext{
${ }^{21}$ For Sen, the 'reasons to value' that people use will certainly depend on their culture, and he seems in general to accept their reasons (though not always). Since in some cultures the objects of value include features of systems, perhaps CA can have ethically quasi- non-individualist variants (e.g. 'I value the capability to live in a society that continues the traditions of my forefathers').
} 
the vaunted 'discovery' of identity is through (fallible) reasoning. Nussbaum does similar service but from a more substantial basis.

Sen declines, for carefully considered reasons, to present or even discuss a list of central capabilities; but that would be one path to thinking further beyond choiceutility-freedom frameworks. Nussbaum, for example, through that exercise conveys and stimulates a richer picture of aspects of being human (for example in her attention now to religion), whether or not one agrees with her particular formulations and prioritizations. She takes us much further from the world of the economic man of no specified and varied emotions: no friendship, emnity, pride and anger, loves and fears.

Giri and van Staveren see in Sen's CA a one-sided focus on reason and a relative neglect of the emotions and empathy, the emotional experience and maturation, required for and normal to human life. Reason by itself is not enough to sustain a reasonable society. That 'requires a far fuller appreciation and acceptance and invitation of the other into one's own' writes Giri (2000, p. 1014), who argues that the still strong self-as-distinct-from-other contrast which Sen uses becomes limiting. Thus Sen's sympathy and commitment categories may as yet figure like optional extras in the schema, not as essential parts of a healthy human being; and so his discussion of what can promote them comes rather in passing (Sen, 1999b). The idea that the self needs sympathy and commitment towards 'itself' likewise remain peripheral (Sen, 1999c; Giri, 2000).

In Sen's picture, the agent's well-being consists of fulfilment of those purposes she has reason to value. What if those values are misplaced, what if they neglect much that is vital (affiliation, family life, community involvements)? In the tradition of welfare economics, SCA does not involve an empirical investigation of what actually brings well-being and of what sorts. It is centrally a set of propositions about the space for evaluation (components 1 to 4 in the list in Section 3 above), espousing a different set from that presupposed in mainstream welfare economics but sharing with it a maxim of the predominant importance of choice, beyond which relatively little empirical investigation is needed. ${ }^{22}$

Giri and Carmen hold further that Sen's O-capability approach has not attended to capability dynamics, the self-development potential of persons or the potential for mobilized, group learning; and that it, so far at least, connects insufficiently to building

\footnotetext{
22 In mainstream economics, choice is presumed to reflect preference and/or to give maximum attainable utility.
} 
capacity for personal and social action, change and transformation. Its conception of capability remains vacuous, a liberal shell rather than a liberationist map.

Sen argues that the incompleteness of his $\mathrm{CA}$ is in some respects a merit, leaving it not required to declare answers where none are (yet) available, compatible with various schools of thought, and hospitable to public debate. However, while the absence of a theory of personhood and agency is a deficiency rather than a defect, compatibility with defective theories-such as Economic Man-would be no virtue; and we saw residues of that theory ensconced in the spaces left in SCA by lack of a more conscious and elaborate theory of the person.

Would SCA have to change much to become of greater interest in a conversation with non-economist social scientists? The various gaps and deficiencies in conceptualizing well-being and personhood might well be remediable to give something that remains recognizably a variant or descendant of CA. Some other authors on capabilities and human development-perhaps including sections of the HDRs fertilized by the richer Basic Human Needs tradition and the study of care-go further than Sen. Irene van Staveren's The Values of Economics is an important example, which could be subtitled: 'Adding attention to care, will, emotion, deliberation, and interaction, to humanize economics and human development theory'. A significant emergent research programme exists in such areas, on the content of both agency and well-being, and their reflection in welfare evaluation and public policy deliberation.

\section{FREEDOM}

Sen's work seems to centre now on 'development as freedom'. His book of that name stresses the instrumental roles of both negative and positive freedom, while the Human Development Report 2000, for which he provided the conceptual framework, posits that 'Human freedom is the common purpose and common motivation of human rights and human development' (p.2). Everyone is assumed to prioritize freedom, if they are rational.

Sen is explicit that values of justice and care can and should be part of persons" agency objectives and commitments, and that CA does not provide or substitute for a fuller theory of justice, which must heed many other types of information. There are some grounds for concern however about the manner of his prioritization and conceptualization of freedom. 


\subsection{The relative importance of 'freedom' and living: capability versus func- tionings}

CA has always been oriented to 'positive freedom', the possibility to do. While granting that capability is not the only relevant focus in evaluation, Sen stresses capability, ability to do various things, more than functionings, what is actually done. ${ }^{23}$ Is this evaluative stress on capability excessive? When Dreze \& Sen (1995) repeatedly stress the importance of 'being clear about ends and means' (e.g. p.12), downgrading economic growth and income as ultimate ends, should we follow them when they exalt [O-]capability, above or even regardless of functionings (e.g. p.13)?

Consider the components of the Human Development Index. The component of GDP per capita (adjusted for purchasing power) measures capability not functionings; it questionably takes income as a proxy for all other capabilities than those primarily determined by education and health. Concerning the other components, do we value health and education because 1 . they provide capability for choice, or 2 . they provide capability for a good life, or 3. for themselves? Education possibly is more valued as supporting capability, though also very often as good in itself. Health surely is substantially valued for itself: as a functioning or functionings. It may be taken as a proxy for many dependent capabilities, but this is not all: health is important in itself, not merely for its effects on other things (which could be compensated for by various means).

Consider too the issue of consumerism and the possible limits to human development from societal preoccupation with material opulence. A theory of human development must attend to functionings-how people actually spend their lives and are affected by their consumption-not only O-capabilities, how they notionally could live with all the information, technology and products available to them. Studies show the extent of, for example, professional over-work and mass addiction to television and pornography in high O-capability countries. Overemphasis on choice compared to achievements could become a reductive focus, counter to Sen's long-term thrust to validate many types of information besides utility levels.

Sen takes functionings as the category that reflects the concern for how people actually live, and capability as reflecting the concern that we should consider how free

23 See e.g. Sen, 2000, pp. 3-4, 24, 29. However we saw that the HDR 2000's Glossary (p.17) defines human development, if somewhat obscurely, in terms of both capabilities and functionings. It adds: 'Human development thus also reflects human outcomes in these functionings and capabilities' (p.17). 
people are, what real options they have in terms of functionings. But freedom should also be assessed by looking directly at functionings. Freedom does not mean only the ability to be healthy, but actually being healthy, not mentally and physically infirm, free of infirmity. And how sufficient would be a conception of freedom that ranks highly an educated, well-paid, still physically healthy person habituated, perhaps even addicted, to $30-40$ hours of television and video-viewing per week?

The prioritization in Sen's CA of capability over functionings can however be understood as a proposed policy principle rather than as a theory of well-being: a principle that we should leave people to decide for themselves about if and how to use a capability, whether or not their choices bring them well-being or goal fulfilment.

\subsection{What does freedom mean? More than the range of (valued) choice}

For Sen, capability means the range of (valued) attainable functionings n-tuples/ vectors/packages, and represents the extent of positive freedom. A series of grey and problem areas arise for this $(\mathrm{RO}(\mathrm{V}) \mathrm{C}$, range of valued choice) concept of positive freedom. $^{24}$

First, there can be difficulties in specifying the meaning of 'attainable'; for example, attainable under what assumptions about ability to perceive opportunities, ability to formulate choices, ability to make choices, and ability to act? These obscurities attach to the concept of freedom and are not specific to the capabilities formulation; and while they sometimes become serious are not fundamental for our present purpose.

Second, education comes to have a special priority, like health, so that people not only have the opportunity to become educated but use it. Those various capabilities (in the substantive S-capability sense) to perceive, formulate, reflect, choose and act must be in place before a range-of-(valued-)choice conception of freedom makes sense. Otherwise there is the danger that every expansion of the range of trivia or nonsense available for purchase, and every loss of moral inhibition, becomes automatically seen as an extension of human freedom and human development. Sen does stress agency aspects of being, but arguably underplays the skills and personality formation required for choice as opposed to bondage and, in Ananta Giri's terms, for self-nurturance, selfdevelopment, self-extension and self-transcendence, including for assuming responsibility and not only demanding freedom (Giri, 2000).

\footnotetext{
${ }^{24}$ Sen certainly also puts value on negative freedom (e.g. Sen, 1985).
} 
Third, not merely is possession of substantive capabilities to formulate, choose and so on a prerequisite for the $\mathrm{RO}(\mathrm{V}) \mathrm{C}$ conception to have plausibility, and not guaranteed, it is in danger of being undermined by the $\mathrm{RO}(\mathrm{V}) \mathrm{C}$ conception. There are two levels of choice: a) the busy comparisons of the consumer in the emporium; and b) the level from which the busy consumer may be eternally diverted - including the choice not to busy oneself with trivia. This is part of an explanation of the Easterlin paradox, the lack of evidence that higher wealth produces sustained higher happiness or satisfaction. If some needs remain not recognised or fulfilled then we get the illusion of limitlessness of (especially material) desires, as substitutes are sought endlessly and in vain. A theory of capability not linked to a theory of need might be hollow and liable to mislead (cf. Hamilton, 1999; Walsh, 2000).

The HDR 1998 starts from the principle that we 'must aim at extending and improving consumer choices too, but in ways that promote human life' (p.1). So we require criteria for promotion that go beyond choice alone, in other words some conception of good human life. But its conceptual framework chapter tiptoes with extraordinary brevity past a few theories of consumption, then simply declares that 'This Report uses the understanding generated by all the perspectives to explore the impact of consumption on human lives from many angles' (p.40) and adopts the principle of consumer sovereignty without delimitation of its appropriate scope. HDR 1998 puts religions' warnings against material desires into a box, and skirts these too.

Desire is sometimes bondage. In South Africa, the current spreading of large casinos countrywide raises people's range of choices, formally speaking. New casinos are helpfully located within easy reach of the major population concentrations, the black townships, and subsidized bus services are provided. This is accompanied by a rise of compulsive gambling, with damage to families and many of the gamblers. ${ }^{25}$ Thus some other conceptions of freedom concern control of desire and renunciation of illusion, through the understanding of causation, 'the recognition of necessity'. A conception of freedom could require a conception of reason.

Fourthly, even given the prerequisite substantive capabilities for choice, ranking situations according to the range of choice provided—so that e.g. the more sexual part

\footnotetext{
25 'A study by the Human Sciences Research Council, a think-tank, found that poor punters were losing more than they could afford, and that one gambler in seven borrowed to bet... The official line is that gambling is better legal.' (The Economist, April $7^{\text {th }}, 2001$.)
} 
ners one can choose the better-would not be fully convincing. What one is choosing between is important. The HDRs and Sen stress valued choices (e.g. HDR 1996, p. 49: 'people's capabilities to lead the lives they value'); but apart from cases when people's values are immature-as for the half of humanity that are children - what of where values are twisted, for example as in the cases Sen used to query the criterion of felt utility? Sen habitually refers to what one 'has reason to value'; for example in his chapter in the HDR 2000 (p.20): 'The human development approach is concerned, ultimately, with all the capabilities that people have reason to value'. This flexible, ambiguous, potentially populist phrase, if left with no criterion for what is good reason, could represent a liberal 'choice for choice'. Further judgements on what it is to be human are left for choice by - 'people'? Some people have reasons to value killing their enemies and the 'defiled'. Here again other authors-including the Universal Declaration of Human Rights, and the HDRs themselves with their de facto lists of basic needs/rights-have more to say. In fact SCA's distancing from felt utility, and its concern to provide other criteria for allocation or steering in public policy, make it less populist than its language sometimes suggests.

Fifthly, choice can be costly and a burden. Hypertrophy of options need not increase well-being, even if one has strong S-capabilities to skim, scan and select. Sen observes this on occasion (e.g. 1992, pp. 59,63), and could reply that the ways of life in the attainable set are inclusive of the choices they involve and the associated costs and stresses. The point remains that adding more choices can be undesirable, when either $\mathrm{A}$. it ties one up in excess choice processes, or B. more radically, it distracts one and distorts one's personality, not just diverts an unchanged personality. Case A can be formulated to fit a $\mathrm{RO}(\mathrm{V}) \mathrm{C}$ conception; case $\mathrm{B}$ might undermine it.

Sixthly, freedom as the ability to achieve more and more is insufficient if others' freedom is not considered. Sen is strongly oriented to this point but, remarks Giri, his version of $\mathrm{CA}$ does not help much here. Its picture of agents is too thin to characterize, explain or promote sympathy and commitment. A human development approach needs more.

\section{ROLES AND PROSPECTS FOR THE CAPABILITY APPROACH}

The capability approach helps to broaden economics beyond commodities and open it to more interdisciplinary cooperation (Gasper, 2000b); it stimulates useful empirical work and policy initiatives. This combination of contributions is rare. One 
wishes then to be clear on how to upgrade or complement $\mathrm{CA}$, reduce mishandling, and assist evolution on to an improved next generation or successor.

The first and greatest role of Sen's CA is in the battle against productionism and obsession with GNP, by opening doors for more types of information, and stressing that how people live (the category of functionings) is more important than what they earn or spend. It is not the only route to that destination, but has helped many more people to reach it. SCA is a great advance over mainstream economics welfare theory, let alone the GNP/GDP worship in some economic policymaking. To be operational, simplified versions are needed, and CA provides the basis for a workable alternative set of proxies and indicators which surpass those in mainstream economics. Like all approaches, it can become a frozen substitute for thought, a new liturgy. But it can also function as a fruitful set of prompts towards creative examination of issues and situations.

The second main role has been to stress via the category of [O-]capability the value of freedom, the right to make one's own choices, judicious or mistaken. Here GDP per capita re-enters in the HDI, as a (flawed) proxy for agency freedom. By prioritizing the capability category CA goes further, but this prioritization is to be understood as a policy principle rather than as a theory of well-being: a stance that we should leave people to decide for themselves, whether or not this brings them well-being. Even if everyone in their own life gave normative priority to the level of functionings, in the public arena a one-step back conception is often required.

These broad contributions from CA are particularly useful for say an economist in a Ministry of Finance or aid agency, to think beyond economic growth, even distribution-adjusted growth. They are relevant but not sufficient for policy makers, creators, planners, managers or evaluators in any sector. For finer grade tasks we need finer toothed combs.

Sections 4 through 6 have suggested that SCA's theory of personhood and the self give an insufficient basis for theory and policy-making towards human development and well-being. A thinnish theory of personhood, including an underdeveloped picture of types of mental state, can contribute to (and then in some cases be reinforced by): unsatisfactory choices of terms, underdeveloped pictures of both well-being and agency, and an overstated and potentially monotheistic normative program of strong priority to an insufficiently refined conception of positive freedom. A conception of freedom requires also conceptions of reason and need. Given the limits to the range-ofvalued-choice (ROVC) conception of freedom, attention to well-being requires a major 
emphasis on functionings, not exclusively or predominantly on capabilities in ROVC terms. The treatment of functionings needs a Frommian attention to be-ing, not only to havings defined as be-ings. The treatment of agency needs to be more than an add-on to a still partially utilitarian conception of well-being. Without such deepening, 'Human Development' conceived as ever greater [O-] capability risks becoming absorbed into the hegemony of commodity production and consumerism.

Diane Elson (1997) has captured several key trends and issues for Human Development theory, in terms close to Apthorpe's and van Staveren's. The HD work has valuably moved beyond the narrow and often unrealistic views of people in neoclassical economics, 'new growth theory' and discussions of 'human capital'. It sees people as multi-dimensional but limited agents, and as the ends and not only the means for development. It needs to go further, to view people as actors bearing multiple social roles, and cultures, beyond those of consumer, investor, chooser. Fig. 4 summarizes her points.

\begin{tabular}{|c|c|}
\hline \multicolumn{2}{|c|}{ Figure 4: Trends and Issues for Human Development Theory } \\
\hline From seeing people as: & To seeing them as: \\
\hline $\begin{array}{l}\text { (i) masterful choosers amongst given } \\
\text { possibilities (the view in standard } \\
\text { neoclassical economics); } \\
\text { and/or } \\
\text { (ii) as deployers of and investors in 'human } \\
\text { capital' assets (themselves) which are no } \\
\text { different from any other assets (the new } \\
\text { growth theory view); }\end{array}$ & $\begin{array}{l}\text { (iii) having changeable, socially influenced, } \\
\text { possibilities, and differing, changeable, } \\
\text { capacities for choice; (the HD school) } \\
\text { and } \\
\text { (iv) as people, producers, group members, } \\
\text { culture bearers, men/women, old/young, } \\
\text { parents/children ... (extending the HD } \\
\text { school). }\end{array}$ \\
\hline
\end{tabular}

With Giri and van Staveren she reminds us that: 'it is not enough to call for more public investment in health and education, and more income transfers to offset entitlement failure. It is necessary also to examine the nature of the social institutions through which personal care is provided to those who cannot care for themselves. ...The key issue is how to synthesize individual self-realization and concern for others. How can we avoid the enlargement of individual choices leading to selfishness and a decline in community values and responsibilities?' (Elson, 1997, pp. 66-7).

$\mathrm{CA}$ has helped open up a territory for investigation, within which we see much 
valuable work (see: Robeyns; Alkire, Comim \& Qizilbash). We need to distinguish versions, including: the simpler versions expressed in the HDRs, which yet sometimes also go beyond Sen; the version(s) Sen uses for many working purposes; his full system of thought, including much besides CA; Martha Nussbaum's alternative; and further work. How much long-term advance these versions and the whole approach will allow must simply remain to be seen.

Ul Haq warned that 'stagnant ideas die quickly... It is critical, therefore, that the intellectual evolution in the human development area be stimulated further... [The] human development ideas ... should be debated, criticized, brutalized and evolved further in many directions' (1998, p. 225). Sen joins the call to keep HD a dynamic stream, as ul Haq did, 'not a stagnant pool' (Sen, 2000b, p. 23). CA may require periodic anti-freeze, and additional inputs different in type from Sen's. I have found the work of, for example, Carmen, Doyal \& Gough, Nussbaum and van Staveren helpful. The latter for example greatly extends the insights in Sen's famous 'Rational Fools: A Critique of the Behavioural Foundations of Economic Theory'-by drawing on actual, varied, extensive behavioural evidence. Human development theory in turn requires additional bases besides CA, such as from the work of Giri, Maslow and Max-Neef. 23). Making and keeping various channels of communication open, being a broad(er) forum and still a research programme, is the challenge ahead for human development theory.

\section{REFERENCES}

Alkire, S. (2002) Valuing Freedoms (Oxford Univ. Press., Oxford and New York).

Alkire, S., Comim, F., \& Qizilbash, M. (eds., forthcoming) Papers from the June 2001 University of Cambridge conference on Sen's Capability Approach (Cambridge Univ. Press, Cambridge).

Anand, S. \& Sen, A. (2000) The Income Component of the Human Development Index, J. of Human Development, 1(1), pp. 83-106.

Apthorpe, R. (1997) Human development reporting and social anthropology, Social Anthropology, 5(1), pp. 21-34.

Argyle, M. (1987) The Psychology of Happiness (London, Methuen).

Bauman, Z. (1988) Freedom (Open University Press and University of Minnesota Press).

Cameron, J. (2000) Amartya Sen on Economic Inequality, The Need for an Explicit Critique of Opulence, $J$. of International Development, 12(7), pp. 1031-1045. 
Carmen, R. (2000) 'Prima Mangiare, Pois Filosofare', J. of International Development, 12(7), pp. 1019-1030.

Cohen, G.A. (1993) Equality of What? On Welfare, Goods and Capabilities, in: Nussbaum, M., \& Sen, A. (eds.) The Quality of Life (Oxford, Clarendon), pp. 9-29.

Douglas, M., \& Ney, S. (1998) Missing Persons: A Critique of the Social Sciences (Berkeley, Univ. of California Press).

Doyal, L., \& Gough, I. (1991) A Theory of Need (London, Macmillan).

Drèze, J., \& Sen, A. (1995) India: Economic Development and Social Opportunity (Delhi, Oxford Univ. Press).

Elson, D. (1997) Economic Paradigms Old and New: The Case of Human Development, in: R. Culpeper et al. (eds), Global Development Fifty Years after Bretton Woods (Basingstoke, Macmillan), pp.50-71.

Fromm, E. (1978) To Have Or To Be? (London, Jonathan Cape).

Gasper, D. (1996) Needs and Basic Needs - a clarification of foundational concepts for development ethics and policy, in: G. Köhler et al. (eds.) Questioning Development (Marburg, Metropolis), pp. 71-101. Longer version as Working Paper 210, Institute of Social Studies, The Hague.

Gasper, D. (1997) Sen's Capabilities Approach and Nussbaum's Capabilities Ethic, J. of International Development, 9(2), pp. 281-302.

Gasper, D. (2000a) Development as Freedom: Moving Economics Beyond Commodities - The Cautious Boldness of Amartya Sen, J. of International Development, 12(7), pp. 989-1001.

Gasper, D. (2000b) Interdisciplinarity - Building Bridges and Nurturing a Complex Ecology of Ideas. Working Paper 162, Madras Institute of Development Studies.

Giri, A. (2000) Rethinking Human Well-Being: A Dialogue with Amartya Sen, J. of International Development, 12(7), pp. 1003-18.

Gore, C. (1997) Irreducibly Social Goods and the Informational Basis of Amartya Sen's Capability Approach, J. of International Development, 9(2), pp. 235-250.

Gough, I., \& Thomas, T. (1994) Why Do Levels of Human Welfare Vary Among Nations? Internat. J. of Health Services, 24(4), pp. 715-48.

Haq, Mahbub ul (1998) Reflections on Human Development, $2^{\text {nd }}$ edition (Delhi, Oxford Univ. Press).

Hamilton, L. (1999) A Theory of True Interests in the Work of Amartya Sen, Government and Opposition 
Harriss-White, B. (1995) Economic Restructuring: State, Market, Collective and Household Action in India's Social Sector, European J. of Devt. Research, 7(1), pp. 124-47.

Lipsey, R.G. (2001) Successes and failures in the transformation of economics, $J$. of Economic Methodology, 8(2), pp. 169-201.

Nussbaum, M. (2000) Women and Human Development (Delhi, Kali for Women, and Cambridge, Cambridge Univ. Press).

Nussbaum, M., \& Sen, A. (eds., 1993) The Quality of Life (Oxford, Clarendon).

O'Neill, O. (1996) Towards Justice and Virtue - A constructive account of practical reasoning (Cambridge, Cambridge Univ. Press).

O’Neill, O., (2000) Bounds of Justice (Cambridge, Cambridge Univ. Press).

Parsons, T. (1937) The Structure of Social Action (New York, Free Press).

Pressman, S., \& Summerfield, G. (2000) The Economic Contributions of Amartya Sen, Review of Political Economy, 12(1), pp. 89-113.

Ravallion, M. (1997) Good and Bad Growth: the Human Development Reports, World Development, 25(5), pp. 631-8.

Robeyns, I. (2000) An unworkable idea or a promising alternative? Sen's capability approach re-examined. Discussion paper 00.30, Centre for Economic Studies, University of Leuven.

Scitovsky, T. (1992) The Joyless Economy, $2^{\text {nd }}$ edition (New York, Oxford Univ. Press).

Sen, Amartya (1982) Rational Fools: A Critique of the Behavioural Foundations of Economic Theory, in: Sen, Choice, Welfare and Measurement (Oxford, Blackwell).

Sen, Amartya (1985) Well-Being, Agency and Freedom, J. of Philosophy, 82, 169-221.

Sen, Amartya (1987) Ethics and Economics (Oxford, Blackwell).

Sen, Amartya (1992) Inequality Reexamined (Oxford, Clarendon).

Sen, Amartya (1993) Capability and Well-Being, in: Nussbaum \& Sen (eds.), pp. 3053.

Sen, Amartya (1999a) Assessing Human Development, in: UNDP (1999) Human Development Report 1999.

Sen, Amartya (1999b) Development as Freedom (New York, Oxford University Press).

Sen, Amartya (1999c) Reason before Identity (Oxford, Oxford University Press).

Sen, Amartya (2000a) Social Exclusion: Concept, Application, and Scrutiny, Social Development Paper no.1, Office of Environment and Social Development, Manila, Asian Development Bank. 
Sen, Amartya (2000b) A Decade of Human Development, J. of Human Development, 1(1), pp. 17-23.

Simonis, Udo (1992), Least Developed Countries - Newly Defined, FS-II 92-404, Research Professorship Environmental Policy, Science Center Berlin.

Staveren, I. van (2001) The Values of Economics - An Aristotelian Perspective (London, Routledge).

Stevens, R. (ed., 1996) Understanding the Self (London, Sage, for the Open University).

Streeten, P. (1995) Foreword to ul Haq (1998).

Sumner, L.W. (1996) Welfare, Happiness and Ethics (Oxford, Clarendon).

Swedberg, R. (1990) Economics and Sociology (Princeton University Press).

UNDP (1990- (annual). Human Development Report (year) (New York, Oxford Univ. Press).

UNDP HDRO (1997) Analytical Tools for Human Development. On UNDP Human Development Report Office website.

Walsh, V. (2000) Smith After Sen, Review of Political Economy, 12(1), pp. 5-25. 